\title{
The approach to determining vulnerable elements in critical energy infrastructures
}

\author{
Natalia Beresneva, Natalia Pyatkova ${ }^{1}$ \\ Melentiev Energy Systems Institute, 130 Lermontov str., Irkutsk, Russia
}

\begin{abstract}
The paper presents the main provisions of the methodology for identifying vulnerable elements in the fuel and energy complex, which is studied as a set of industry critical energy infrastructures. This methodology is based on the use of industry models system in the fuel and energy sector, on the analysis of the interconnected critical energy infrastructure's work in normal functioning and during emergency situations. The paper proposes a schematic diagram for the formation of vulnerable elements list for fuel and energy complex based on critical elements of industries. The scheme of work with a two-level system of models is given. The results of testing the methodology and developed models are presented (illustrative example).
\end{abstract}

\section{Introduction ${ }^{a}$}

Critical infrastructures in accordance with the definitions $[1,2]$ with full confidence include industry energy systems and the fuel and energy complex (FEC), which is an interconnected infrastructure consisting of separate energy systems. This statement is confirmed by the importance of these infrastructures for the country's economy, supported by the need to ensure energy security, characterized as the state of protection of citizens, society, the state and the economy from threats of deficit in meeting their needs for energy resources of acceptable quality, from threats to disruption of uninterrupted energy supply. The main tasks to be solved in this case [3]:

- forecasting the conditions for the functioning and development of energy systems and the fuel and energy complex as a whole, taking into account possible critical and emergency situations;

- assessment of the condition under these conditions;

- identification of "bottlenecks" in the fuel and energy supply systems of consumers;

- the choice of alternatives, directions and specific measures to prevent emergency situations in systems or reduce their negative impact.

The consequences of the implementation of these emergency situations can lead to significant interruptions in reliable fuel and energy supply to consumers, and can cause a shortage of energy resources. This increases the relevance and need for models develop of critical energy infrastructures to

\footnotetext{
${ }^{a}$ Corresponding author : nata@isem.irk.ru
}

identify potential bottlenecks (vulnerable elements of critical infrastructures), assess their criticality for guaranteed and timely supply of energy needs. To conduct research with their help, a methodology for determining the critical (vulnerable) elements for the fuel and energy complex as a whole was developed and tested, presented below.

\section{Methodology for determining critical elements}

Studies to identify the most vulnerable elements (objects) of interconnected critical energy infrastructures (energy systems) are carried out on the basis of optimization of territorial-production models of functioning of the country's fuel and energy complex. In this case, the hypothetical calculated (non deficient or indignant) states of the fuel and energy complex are analyzed. Perturbed states are formed on the basis of single shutdowns of fuel and energy facilities, or for shutdowns of their groups. These disconnections at the model level are realized by a sharp decrease in the production capabilities of the objects, namely, the zeroing of the upper restrictions of the model variables corresponding to these objects. A comprehensive assessment of these conditions is carried out on the basis of their model indicators for various territories and for the analyzed critical infrastructures. For this, the criterion for the effectiveness of each infrastructure is used - relative energy shortages that are developing among consumers. Additionally, it is possible to consider the using of the industries reserve capabilities fuel reserves, reserves of generating capacities in electric and heat power engineering, and the possibility of diversifying fuel at double fuel supply facilities. 
To assess the criticality of the fuel and energy complex object in the framework of optimization calculations, the element significance criterion is used, which characterizes the relative changes in the analyzed model parameters when the functioning mode of this object changes over the entire set of states. Formally, this indicator is given by formulas (1):

$$
Z O_{i}=\sum_{j=1}^{J} Z O_{i}^{j} * Z C^{j}
$$

$Z O_{i}-$ significance of the $\mathrm{i}^{{ }^{\text {th }}}$ the fuel and energy complex object ;

$Z O_{i}^{j}$ - assessment of states according to the $\mathrm{j}^{\text {th }}$ model indicator (relative energy shortage) when the $\mathrm{i}^{\text {- }}{ }^{\text {th }}$ element is turned off ;
$Z C^{j}-$ priority of the $\mathrm{j}_{-}{ }^{\text {th }}$ indicator ;

$J$ - number of analyzed indicators (energy shortage, depletion of reserves, capacity reserves, etc.);

$I$ - plenty disconnected critical elements of the fuel and energy complex.

The research scheme (Fig. 1) is formally represented by three stages:

- the stage for the formation of the strategy for selecting critical objects;

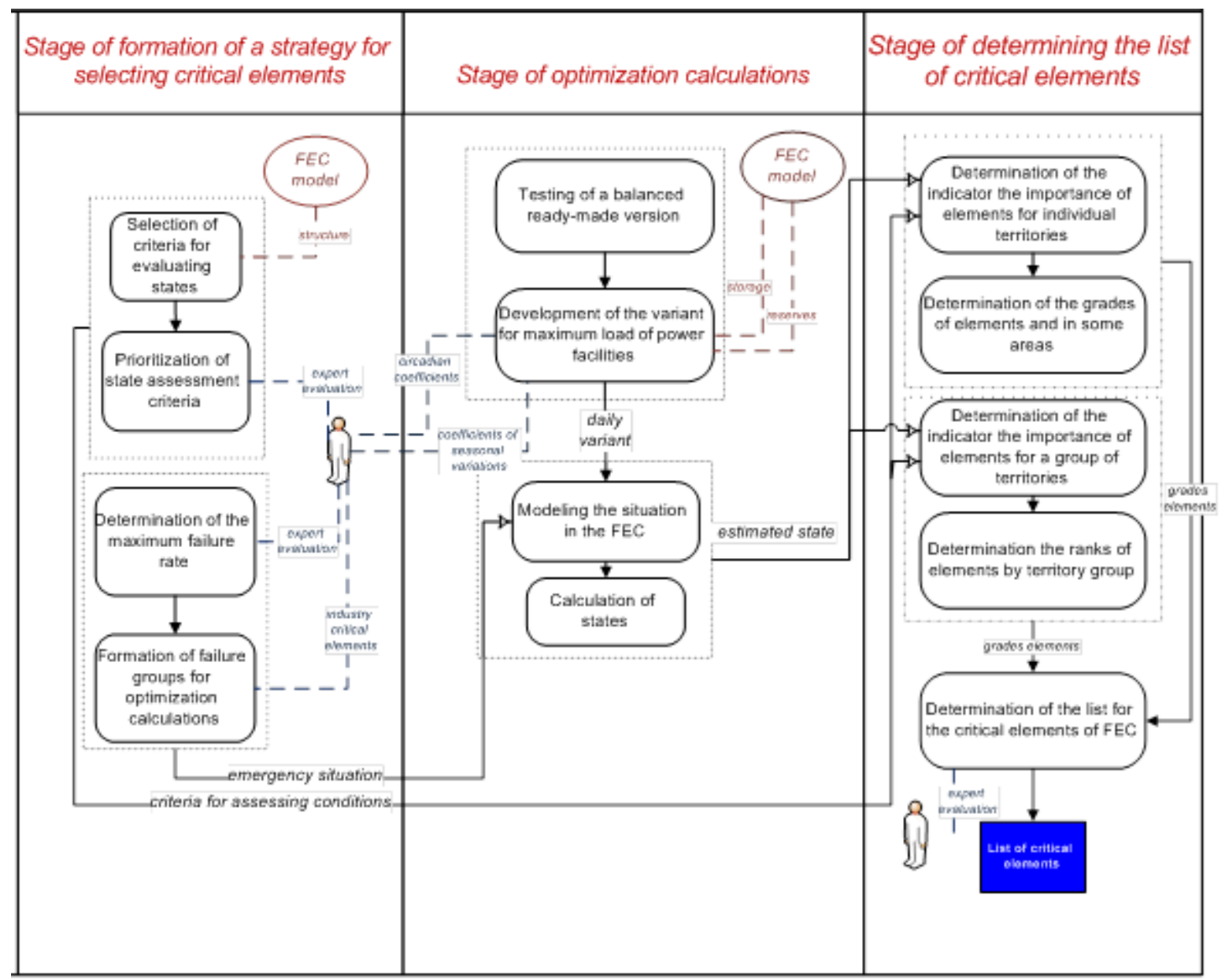

Fig. 1 A generalized search scheme for critical elements in the framework of model calculations

- the stage of carrying out optimization calculations;

- the stage of forming a list of critical objects based on their calculated significance indicators.

At the first stage

- objects of the simulated FEC territorial-production structure are determined;

- groups of disconnected elements are formed for their subsequent inclusion in simulated situations;

- a set of criteria for assessing states (relative model indicators) is formed, the significance of these criteria is determined
- categories of elements criticality and their threshold values are determined;

- emergency situations scenarios are being formed.

At the second stage, optimization calculations of the fuel and energy complex model are carried out, in the framework of which:

- balanced annual version of the statistical information is being debugged;

- the variant for the daily maximum load in energy systems is being debugged; 
- abnormal situations are calculated with various options for disconnecting potential vulnerable elements.

At the third stage, the results of assessing the state of critical infrastructures when disconnecting the specified elements are formed:

- the composition of the analyzed calculated states is corrected by excluding the states with a relative deficit acceptable for the country as a whole for at least one resource;

- criteria for the significance of elements for the territories or their groups are determined;

- the ranks and categories of criticality for the analyzed elements are determined;

- a list of critical elements for the fuel and energy complex is formed.

\section{An illustrative example of testing the methodology}

The methodology was tested on the basis of daily model for the functioning of the fuel and energy complex. Therefore, when choosing critical elements of the fuel and energy complex, three types of daily variants for the model are formed: the average daily balanced option, the maximum load variant for energy facilities, and variant for disconnecting industry-specific critical elements with a maximum workload of facilities. In the last two cases, when deficits arose, model mechanisms of structural redundancy of systems in the form of reservation and diversification of energy resources became active.

This model represents the territory of the country by 79 subjects of the federation. Technologically, model consists of industry subsystems of the energy complex (gas, coal, oil refining (in terms of fuel oil supply), and electricity and heat industries) [4].

A number of experimental calculations were carried out in which, as design conditions, the influence of the disconnection of critical elements of the gas industry [5] on the functioning of the fuel and energy complex as a whole was analyzed. The result of a turn-off of selected gas industry facilities was the under-production of the energy resources considered in the model and, accordingly, their shortage among consumers.

In the whole country, for each switch-off facility in the gas industry, the following situation has developed, Fig. 2.

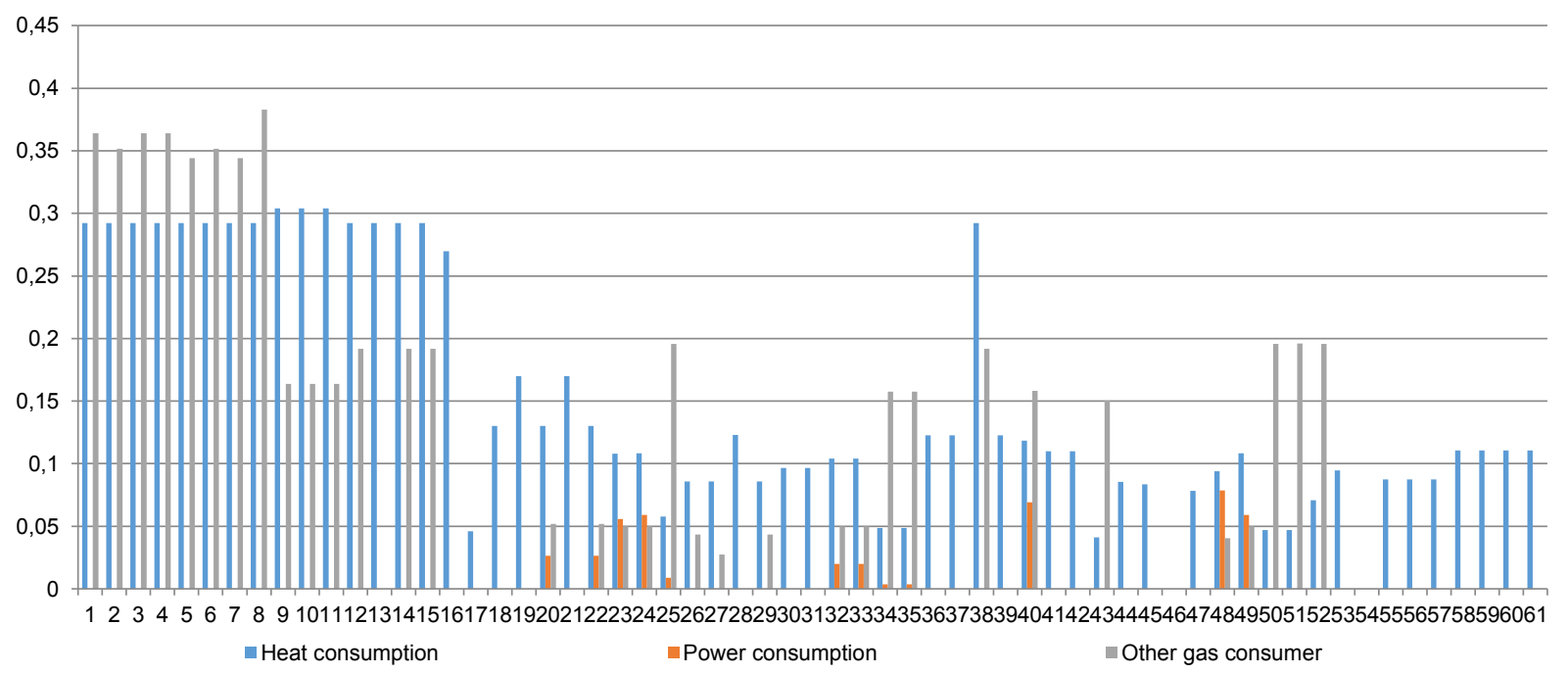

Fig. 2. The relative shortage of energy resources when turning off critical elements of the gas system, the share of units

When determining the coefficients of significance, potential critical elements were discarded, when energy shortages amounted to less than $5 \%$ of the needs. As a result, from the initial list of 61 critical elements in the gas industry, 52 elements remained, the disconnection of which led to more significant shortages (Fig. 3).
The analysis of the obtained graphs showed that the ranked list of critical elements of the gas industry almost corresponds to disconnections of these elements during the mutually agreed operation of all energy systems in a single complex (fuel and energy complex) with rare exceptions. 


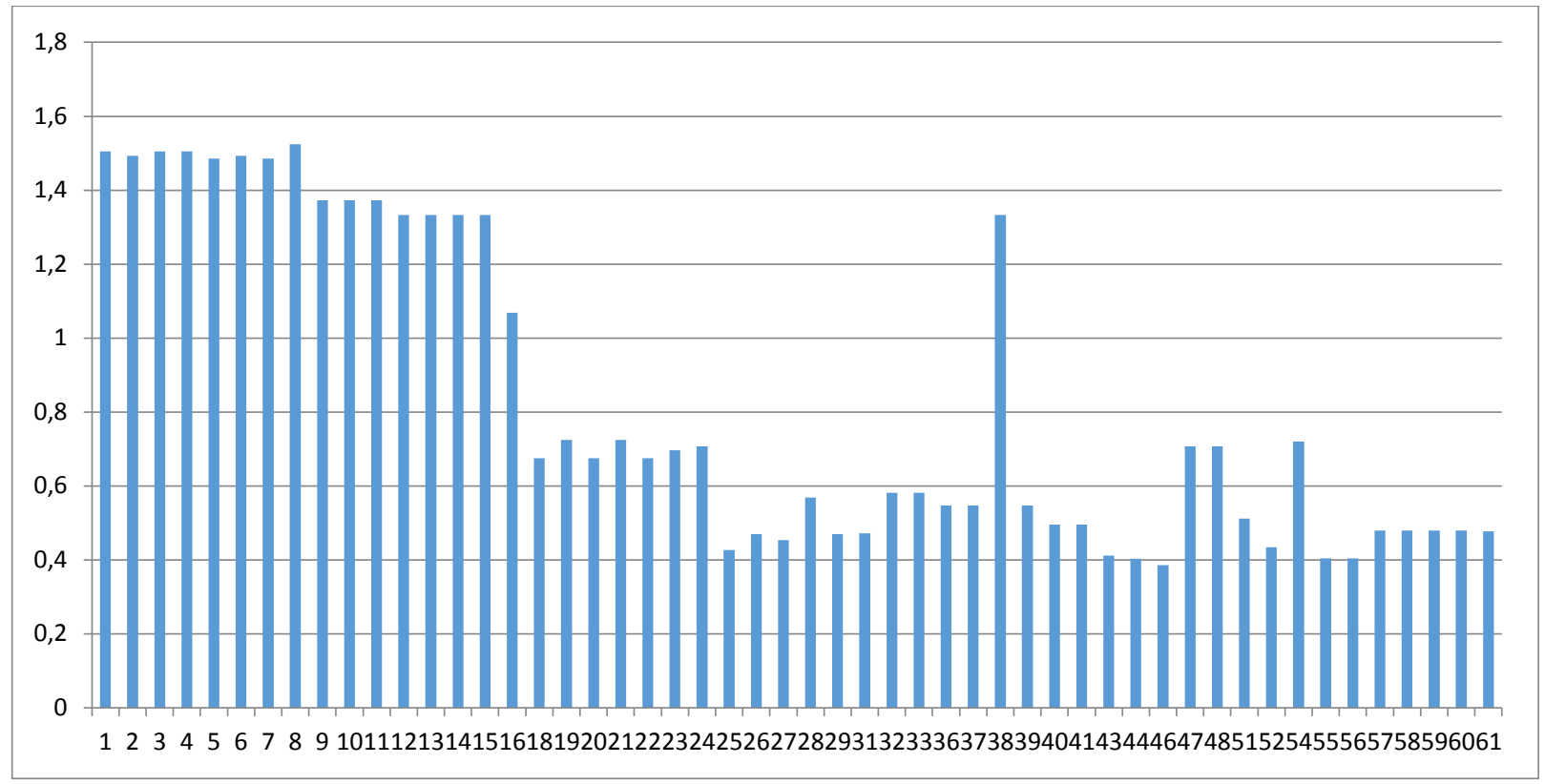

Fig. 3. The coefficients of significance of the critical elements of the gas system

According to the obtained coefficients of significance, three categories of critical elements were identified by their impact on energy supply (by the magnitude of the deficit from their shutdown): 1 category, in which elements causing a total relative deficit of more than $70 \%, 2$ category from 30 to $70 \%, 3$ category - below $30 \%$. The number of critical elements for these groups throughout the country (in federal districts) was distributed as follows (Table 1). A significant deficit was obtained in territories whose fuel and energy balance is focused on the use of natural gas. This is the North Caucasian, Southern and Volga regions, where the number of critical elements of the first category ranged from 17 to 25 .

Table. 1. Classification of critical elements of the gas industry by the impact on energy supply to consumers

\begin{tabular}{|l|c|c|c|}
\hline Federal District & $\begin{array}{c}1 \text { category } \\
(70-100 \%)\end{array}$ & $\begin{array}{c}2 \text { category } \\
(30-70 \%)\end{array}$ & $\begin{array}{c}3 \text { category } \\
(0-30 \%)\end{array}$ \\
\hline Central & 15 & 3 & 34 \\
\hline Northwestern & 14 & 27 & 11 \\
\hline South & 17 & 20 & 15 \\
\hline North Caucasian & 25 & 17 & 10 \\
\hline Volga & 17 & 15 & 20 \\
\hline Ural & 6 & 7 & 39 \\
\hline Siberian & 5 & 3 & 44 \\
\hline Far Eastern & 3 & 49 & - \\
\hline
\end{tabular}

Further, critical elements were considered according to the technological criterion: sources (gas production enterprises) (Fig. 4), compressor stations (Fig. 5), sections of main gas pipelines (Fig. 6). The coefficients of significance of these elements differ in the depth of the deficit caused by them in the territories under consideration. A significant deficit causes shutdowns of the compressor stations and individual sections of gas pipelines. 


\section{Gas sources}

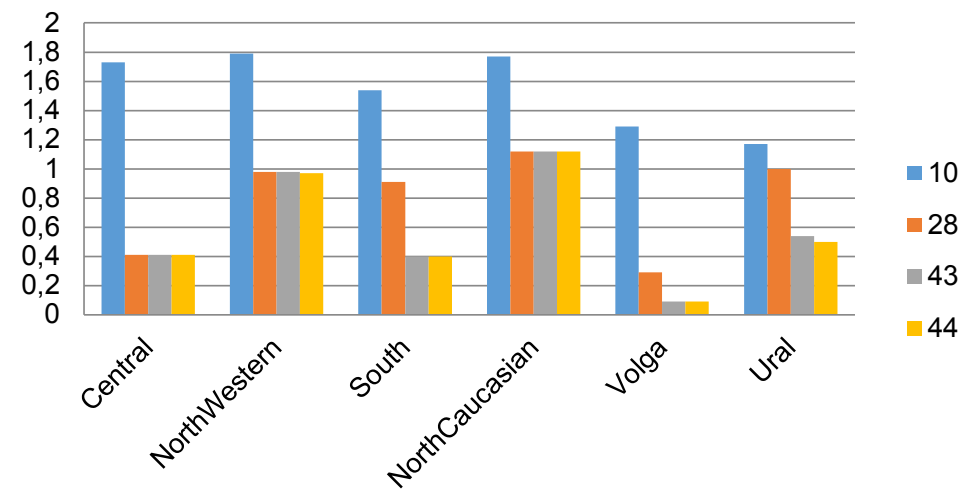

Fig. 4. The coefficients of significance of critical elements of the gas system by district

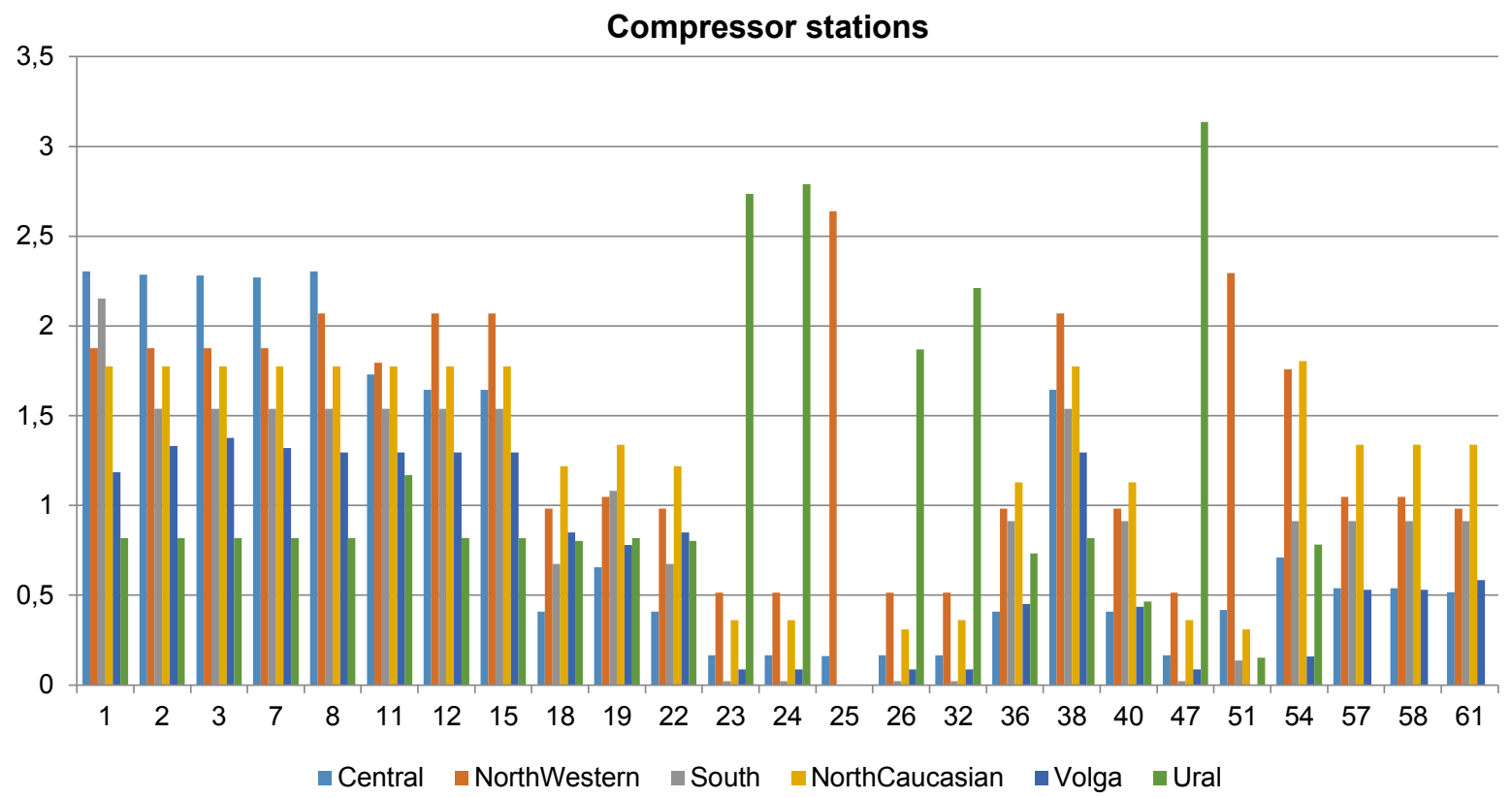

Fig. 5. The coefficients of significance of critical elements of the gas system by district

\section{Gas pipeline sections}

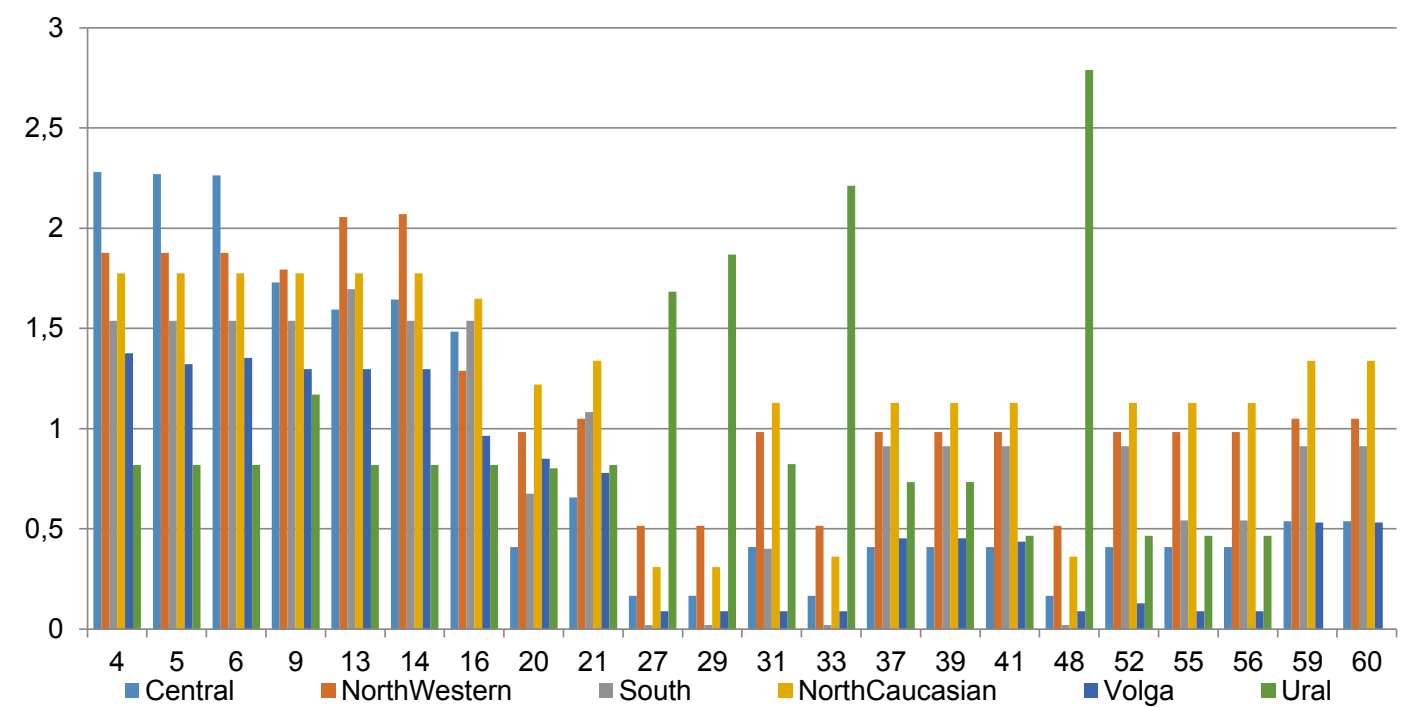

Fig. 6. The coefficients of significance of the critical elements of the gas system by district 
An analysis was made of the frequency (repeatability) of the entry of vulnerable elements into the most critical first category in all federal districts. It turned out that these are mainly compressor stations and sections of gas pipelines, the frequency of which is 5 and 6 , from the sources - one element, the frequency of which in terms of repeatability across the territory was 4.

This example illustrates the results of experimental studies evaluating the significance of elements of the gas industry for reliable energy supply to consumers in a single complex. Similar studies to identify critical elements and reliable energy supply are carried out in the electricity industry $[6,7]$. In the future, it is planned to carry out experimental studies to assess the importance of critical elements of the electric power industry for the operation of the entire fuel and energy complex, as well as combinations of elements of the gas and electric power industries in analyzing the reliability of energy supply to consumers.

\section{Conclusion}

The paper presents the main provisions of the methodology for determining critical (vulnerable elements) in the fuel and energy complex. This methodology is based on the use of a hierarchical system of models of industries in the fuel and energy sector, on the analysis of the interconnected work of industry critical energy infrastructures in normal functioning and during emergency situations. The results of testing the methodology and developed models for studying the influence of critical elements of the gas industry on the mutually agreed work of the energy industries in a single complex are also presented. The coefficients of significance of the elements under consideration, taking into account the systemic effect, are obtained.

The results were obtained in the framework of the project for state assignment of the ESI SB RA No. AAAA-A17117030310451-0, some aspects were worked out in the framework of projects supported by the RFBR grant No. 1907-00351.

\section{References}

1. Kondratiev A. Current trends in the study of critical infrastructure in foreign countries // Foreign Military Review No. 1, 2012, P.19-30.

2. S. Rinaldi, J. Peerenboom, and T. Kelly. Idenlifying, Understanding, and Analyzing Critical Infrastructure lnterdependencies. - IEEE Control Systems Magazine - IEEE, December 2001. - Pp. 1125.

3. Energy security of Russia: problems and solutions / N.I. Pyatkova [et al.], Resp. ed. N.I. Voropay, M.B. Cheltsov; Grew up. Acad. Science, Sib. Department, Institute of Energy Systems named after L.A. Melentieva. - Novosibirsk: Publishing House of the SB RAS, 2011 .-- 198 p.

4. Beresneva N., Pyatkova N. Choosing of the FEC critical objects in model researches of energy security problems and its features // Rudenko International Conference "Methodological problems in reliability study of large energy systems" (RSES 2018). E3S Web Conf. Volume 58, 2018. (DOI 10.1051/e3sconf/ 20185803004)

5. S.V. Vorobev, A.V. Edelev. Application of the method for determining critical elements in networks of technical infrastructures to search for critical objects of the gas transmission network of Russia // Energy Policy, 2018, No. 1, p. 45-51.

6. Iakubovskii D., Komendantova N., Rovenskaya E., Krupenev D., Boyarkin D. Impacts of earthquakes on energy security in the Eurasian economic union: Resilience of the electricity transmission networks in Russia, Kazakhstan, and Kyrgyzstan // Geosciences (Switzerland). Vol.9. №1. ID: 54. 2019. DOI: 10.3390/geosciences9010054

7. Krupenev D. Determination of Critically Objects of Electric Power Systems from the Position of Energy Security // E3S Web of Conferences. Vol.58. ID: 03009. 2018. DOI: $10.1051 / \mathrm{e} 3$ sconf/20185803009. 